\title{
Seasonal variability in ice crystal properties at NorthGRIP: a case study around $301 \mathrm{~m}$ depth
}

\author{
Anders SVensson, ${ }^{1}$ Pauli BaAdSAGER, ${ }^{1}$ Asbjørn PERSSOn,,${ }^{1}$ Christine Sahøtt HVidberG, ${ }^{1}$ \\ MARIE-Louise SIGGAARD-ANDERSEN ${ }^{1,2}$ \\ ${ }^{1}$ Department of Geophysics, University of Copenhagen, Juliane Maries Vej 30, DK-2100 Copenhagen, Denmark \\ E-mail:as@gfy.ku.dk \\ ${ }^{2}$ Alfred Wegener Institute for Polar and Marine Research, P.O. Box 120161, D-27515 Bremerhaven, Germany
}

\begin{abstract}
The aim of this case study is to quantify the seasonal variability in crystal properties and to discuss the reason for the variability. A continuous $1.10 \mathrm{~m}$ long vertical thin-section profile covering approximately five annual cycles has been obtained from the North Greenland Icecore Project (NorthGRIP) ice core at around $301 \mathrm{~m}$ depth. The crystal outline and the $c$-axis orientation of more than 13000 crystals in the profile have been measured on a new Australian automated ice-crystal analyzer. In $2.5 \mathrm{~cm}$ resolution we observe a strong seasonal variability in crystal areas of $>30 \%$ deviation from the average value of $6.7 \mathrm{~mm}^{2}$. Each year, a band of smaller crystals is observed in ice deposited during spring. The area distribution function is found to be close to a lognormal distribution. The crystal areas are compared to the concentration of chemical impurities in the ice; at a $5 \mathrm{~cm}$ resolution, the best correlation is found with the concentration of $\mathrm{Ca}^{2+}$. Our results show no seasonal variability of the average $c$-axis orientation of ice crystals.
\end{abstract}

\section{INTRODUGTION}

It is well known that many parameters in the Greenland ice sheet display a seasonal variability. The oxygen isotope composition of the ice, $\delta^{18} \mathrm{O}$, varies seasonally and is used for absolute dating of the deep Greenland ice cores by counting of individual annual layers. The amount of soluble and insoluble impurities in the ice also shows a seasonal variation (Steffensen, 1988). It is generally believed that crystal growth is related to the impurities in the ice (e.g. Alley and others, 1986; Alley and Woods, 1996), and therefore expected that the crystal sizes also vary seasonally. To our knowledge, a seasonal variation of crystal properties has not been reported until now.

The long-term variability in ice crystal properties, texture and fabric has been established for several deep Greenland ice cores (Gow and others, 1997; Thorsteinsson and others, 1997; Wang and others, 2002). Often the dimensions of the samples used in fabric and texture studies are chosen in order to fit an instrument, rather than to cover a certain time interval in the core. A significant seasonal variability in crystal properties could imply scatter around the general trend, as observed, for example, in the upper $500 \mathrm{~m}$ of the Greenland Icecore Project (GRIP) core (Thorsteinsson and others, 1997). If the seasonality occurs, one could consider sampling in such a way that the results would not be biased by the effect.

The purpose of this work is to quantify the seasonal and the interannual variability in crystal properties in a section from the NorthGRIP ice core at about $301 \mathrm{~m}$ depth. NorthGRIP is a deep drilling site located in North Greenland at $75.10^{\circ} \mathrm{N}, 42.32^{\circ} \mathrm{W}$ with an annual accumulation of $19.5 \mathrm{~cm}$ ice equivalent (Dahl-Jensen and others, 2002). We compare the results with $\delta^{18} \mathrm{O}$ and the concentration of chemical impurities in the ice, and discuss which impurities chiefly influence the crystal properties at NorthGRIP.

\section{METHODS}

A continuous profile of vertical thin sections was obtained from the NorthGRIP ice core in the depth interval 300.85$301.94 \mathrm{~m}$. This depth is within the normal grain-growth regime, where crystal areas increase linearly with time and important polygonization has not yet initiated (Svensson and others, 2003). Inspection of the electrical conductivity measurements (ECM) shows that the sampled ice has no detectable volcanic markers. The profile consists of eleven $10 \times 10 \mathrm{~cm}^{2}$ thin sections, prepared in the freezer at the University of Copenhagen using standard techniques (Hansen and others, 2002). The orientation of the ice core with respect to the core axis is lost when the core is being retrieved, because the drill rotates on its passage through the borehole; therefore, the orientation of the thin sections with respect to this axis is unknown. The logging of the core ensures, however, that the thin sections prepared for this study all have the same (unknown) orientation. In order to produce optimal results, the thin sections have a maximum thickness of $0.5 \mathrm{~mm}$.

The thin sections were measured at the University of Copenhagen on a new automatic $c$-axis analyzer, developed in Australia by D. S. Russell-Head. The instrument produces digital images of the sample at a high resolution of 20 pixel $\mathrm{mm}^{-1}$. The thin section is placed on an $x y$-stage between two crossed linear polarizers, and images of the section are taken with a camera for each $7.5^{\circ}$ rotation of the polarizers. A deviator prism placed between the sample and the upper polarizer enables imaging of light that has traversed the sample at an angle. Crystals change in brightness and color 


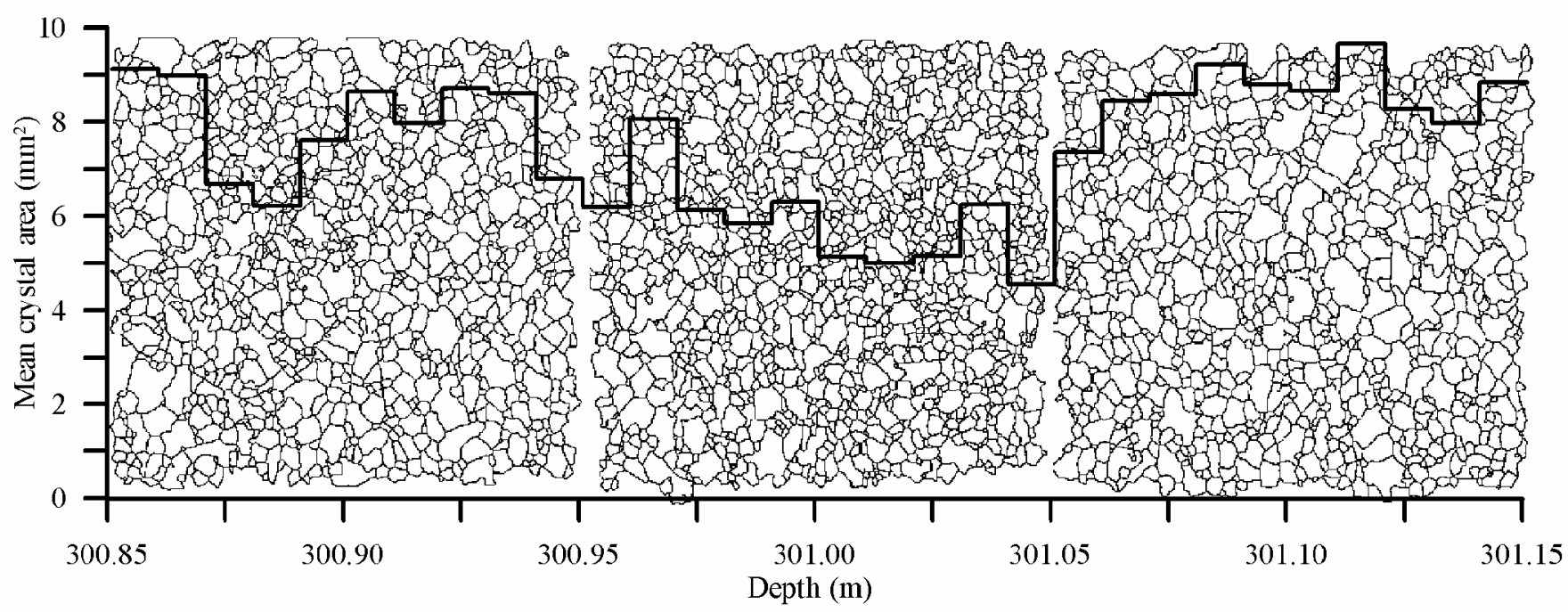

Fig. 1. Crystal outlines of three thin sections and the corresponding average crystal area at $1 \mathrm{~cm}$ resolution (thick step curve). The $5 \mathrm{~cm}$ band of smaller crystals below $301.00 \mathrm{~m}$ depth appears during spring of AD 471 ( see Fig. 2).

as the polarizers are rotated; from these data, the $c$-axis orientation is calculated for each individual pixel in the sample images with accuracy better than $5^{\circ}$. The measurement time is approximately 2 hours for a $10 \times 10 \mathrm{~cm}^{2}$ sample.

From the digital images the outline of the individual crystals in the thin sections is drawn by an automatic method and by manual editing (Hansen and others, 2002). The high resolution allows crystals as small as $0.2 \mathrm{~mm}^{2}$ to be detected. Only complete crystals are included in the analysis, i.e. crystals that intersect with the border of the sample are discarded. After being identified, the crystals are numbered and each crystal is assigned a $c$-axis orientation equal to the mean $c$-axis orientation of all the pixels within the crystal. Sometimes the $c$-axis orientation cannot be determined, if a crystal is too small or if two crystals overlap significantly.

Chemistry samples in $5 \mathrm{~cm}$ resolution have been analyzed for the concentrations of $\mathrm{Ca}^{2+}, \mathrm{Na}^{+}, \mathrm{K}^{+}, \mathrm{Mg}^{2+}, \mathrm{Cl}^{-}$,

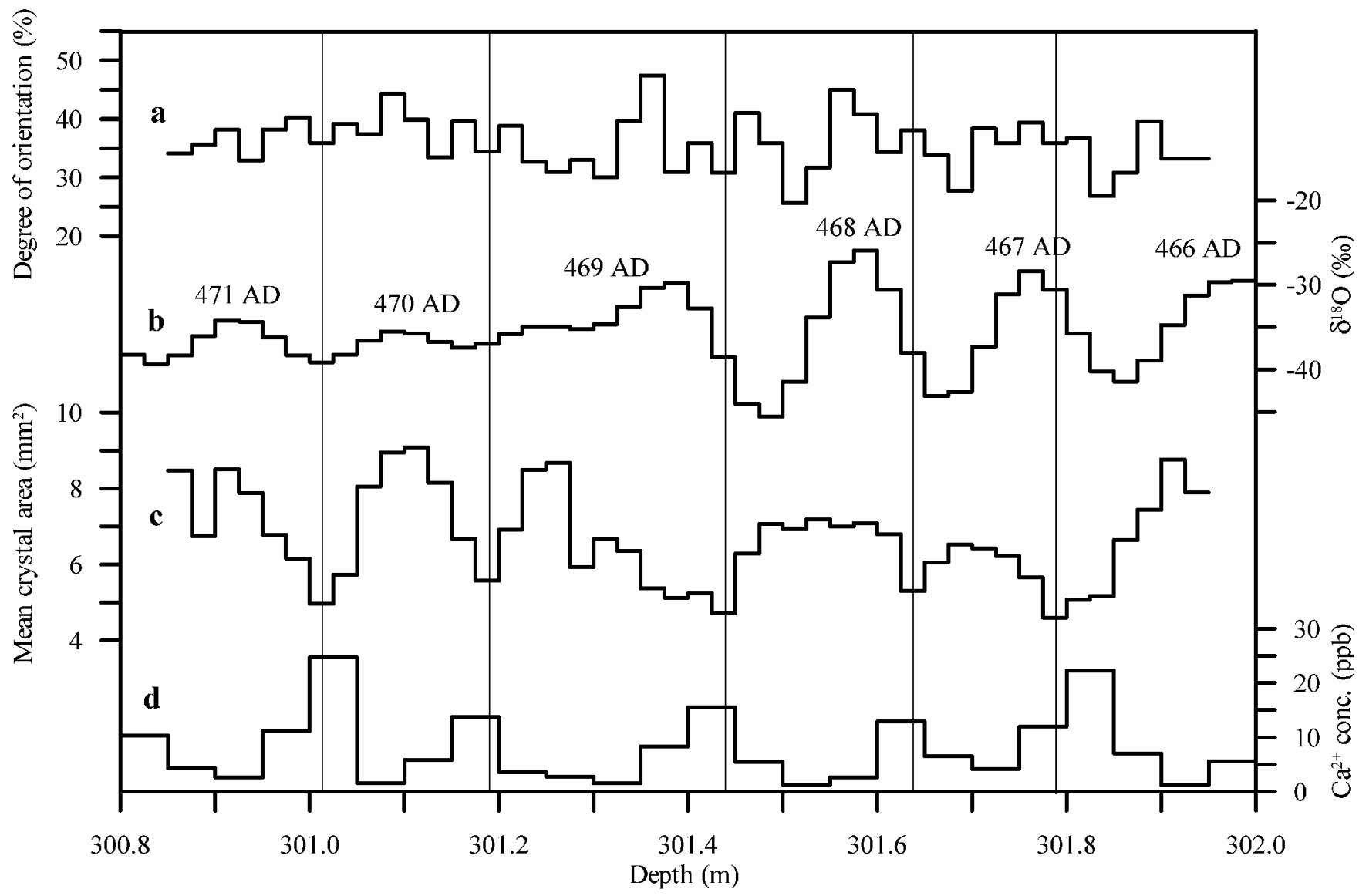

Fig. 2. The temporal variability of various parameters. (a) Degree of orientation of caxes $(R)$. (b) Back-diffused $\delta^{18} O$ (personal communication from S. F. Fohnsen, 2001) with indication of individual years (personal communication from H. B. Clausen, 2001). (c) Mean crystal area. (d) Concentration of $\mathrm{Ca}^{2+}$ in the ice. Vertical lines indicate spring minimums in crystal area. The resolution is $2.5 \mathrm{~cm}$ except for $\mathrm{Ca}^{2+}$, which is at $5 \mathrm{~cm}$ resolution. 


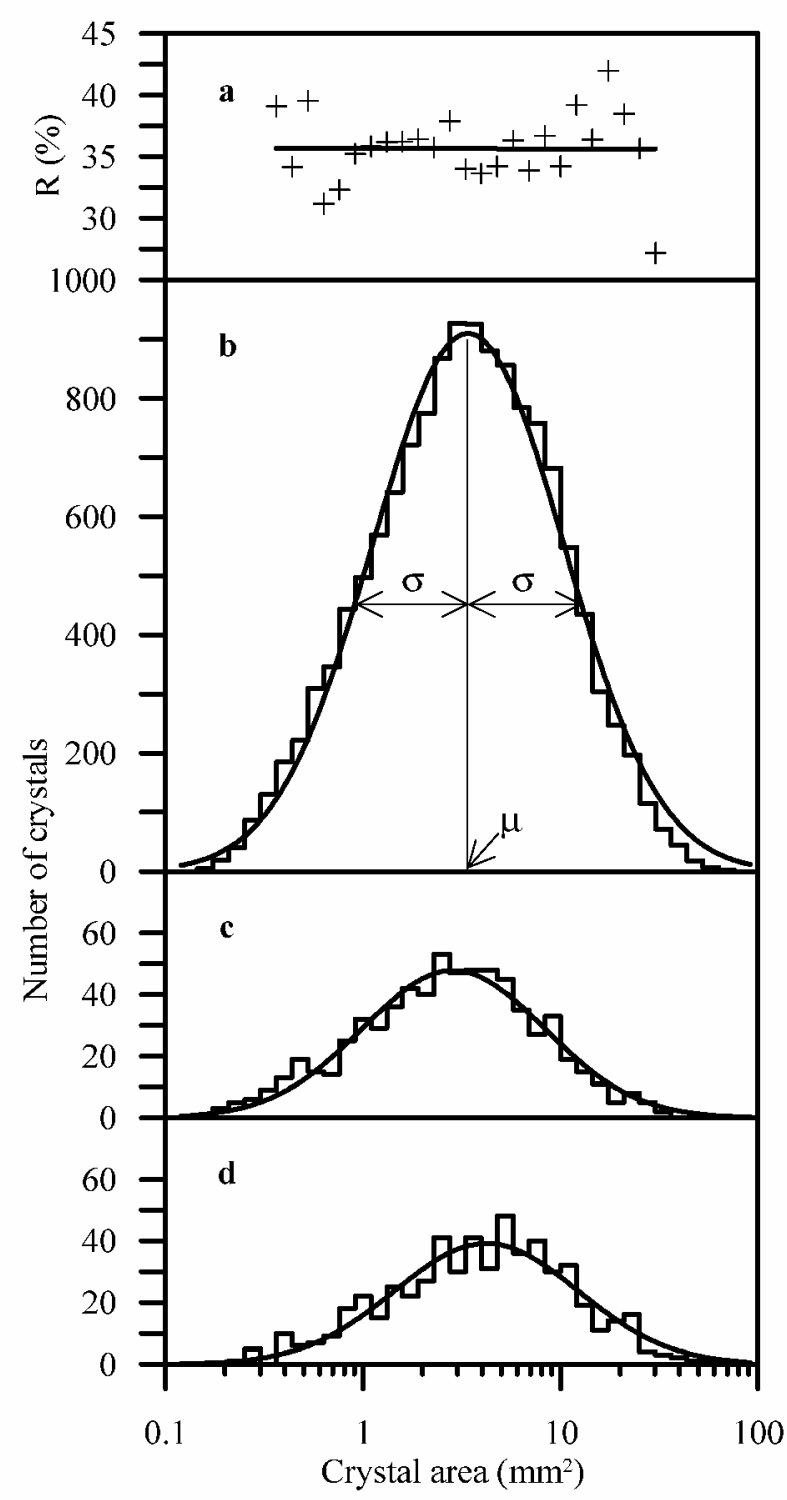

Fig. 3. (a) Degree of orientation of caxes $(R)$ for area classes containing $>100$ crystals (points) and a linear fit (curve). (b) Crystal area distribution of all measured crystals (step curve) and a fitted log-normal distribution (continuous curve) with indication of the log-normal mode $\mu=3.40 \mathrm{~mm}^{2}$ and the log-normal standard deviation $\sigma=3.05$. (c) Same, but for the depth interval 301.00-301.05 m, which contains relatively small crystals ( see Fig. 1). (d) Same, but for the depth interval 301.10-301.15 m with large crystals.

$\mathrm{NO}_{3}{ }^{-}$and $\mathrm{SO}_{4}{ }^{2-}$ in the ice by ion chromatography at the University of Copenhagen as described in Steffensen (1997). Because the $\delta^{18} \mathrm{O}$, the chemistry and the thin-section samples are not obtained from the same ice, there may be an offset in depth between the various measurements of the order of millimeters.

\section{RESULTS}

A total of about 13500 crystals have been detected in the 11 thin sections. The crystal areas fall in the range $0.2-80 \mathrm{~mm}^{2}$, and the mean crystal area of all crystals is $6.51 \mathrm{~mm}^{2}$. The crystal outlines of three thin sections are shown in Figure 1.

Figure 2 shows the average crystal areas, the degree of orientation of $c$ axes, the $\mathrm{Ca}^{2+}$ concentration and the "backdiffused" $\delta^{18} \mathrm{O}$ signal of the ice (personal communication from
Table 1. Correlation coefficients between the mean crystal area and the logarithm of impurity concentrations of the ice at a $5 \mathrm{~cm}$ resolution, and between the mean crystal area and ECM and "back-diffused" $\delta^{18} O$ of the ice at a $2.5 \mathrm{~cm}$ resolution. $95 \%$ confidence level is $0.37(N=20)$

\begin{tabular}{lc}
\hline Parameter & Corr. coeff. \\
\hline $\log \left(\mathrm{Ca}^{2+}\right)$ & -0.76 \\
$\log \left(\mathrm{Na}^{+}\right)$ & -0.55 \\
$\log \left(\mathrm{K}^{+}\right)$ & -0.61 \\
$\log \left(\mathrm{Mg}^{2+}\right)$ & -0.70 \\
$\log \left(\mathrm{Cl}^{-}\right)$ & -0.67 \\
$\log \left(\mathrm{NO}_{3}^{-}\right)$ & -0.31 \\
$\log \left(\mathrm{SO}_{4}^{2-}\right)$ & -0.42 \\
$\mathrm{ECM}$ & 0.23 \\
$\delta^{18} \mathrm{O}$ & -0.12 \\
\hline
\end{tabular}

S. J. Johnsen, 2001) on a depth scale. The "back-diffused" $\delta^{18} \mathrm{O}$ signal is an enhanced, deconvoluted $\delta^{18} \mathrm{O}$ profile, which takes into account the damping of the seasonal signal due to diffusion of water molecules in the firn (Johnsen, 1977). The seasonal variability is thus more exposed in the "back-diffused" $\delta^{18} \mathrm{O}$ than in the measured $\delta^{18} \mathrm{O}$ profile. From reference horizons at other depths in the ice and from counting of annual layers, the sampled ice is known to cover the years AD466-471 (personal communication from H.B. Clausen, 2001).

Each crystal is assigned a depth in the ice corresponding to the position of its center of mass. When grouped into $2.5 \mathrm{~cm}$ depth intervals, the crystal areas show a strong seasonal variability of $>30 \%$ deviation from the average value of $6.7 \mathrm{~mm}^{2}$ (the average of the mean crystal areas within the $2.5 \mathrm{~cm}$ intervals) (Fig. 2). The crystal areas are not directly correlated with $\delta^{18} \mathrm{O}$, but in ice deposited during each spring a local minimum in crystal areas is formed. Although the seasonal variability in crystal areas does not reproduce from year to year, the band of smaller spring crystals appears very consistently. According to the dating of the core, the minor dip in crystal areas at around $301.3 \mathrm{~m}$ depth does not, however, correspond to a spring season. The interannual variability in crystal area is significantly lower than the seasonal variability.

The $c$-axis orientation has been determined for $97 \%$ of the identified crystals in the samples. The overall degree of orientation of the $c$ axes is described by the $R$ parameter (see, e.g., Wang and others 2002), so $R=0 \%$ corresponds to randomly distributed $c$ axes, and $R=100 \%$ corresponds to a single maximum with all $c$ axes being vertical. For all $c$ axes we find $R=35.50 \%$, in accordance with the general $R$ level determined at this depth (Svensson and others, 2003). At a $2.5 \mathrm{~cm}$ depth resolution, the $R$ parameter shows some fluctuation around the average value (Fig. 2), but there is no correlation to any of the other ice-core parameters. We thus conclude that the fabric does not exhibit seasonal variability. In Figure 3a, the $R$ parameter is shown as a function of crystal area. Some scatter is seen around the average level, but with no systematic dependence on crystal area.

As shown in previous studies of Greenland texture (Thorsteinsson and others, 1997; Hansen and others, 2002), the crystal area distribution is close to a lognormal distribution. Our results confirm this for the full ensemble of identified crystals (Fig. 3b), as well as for two subsets, from depth intervals with "small" and "large" crystals (Fig. 3c and d, 


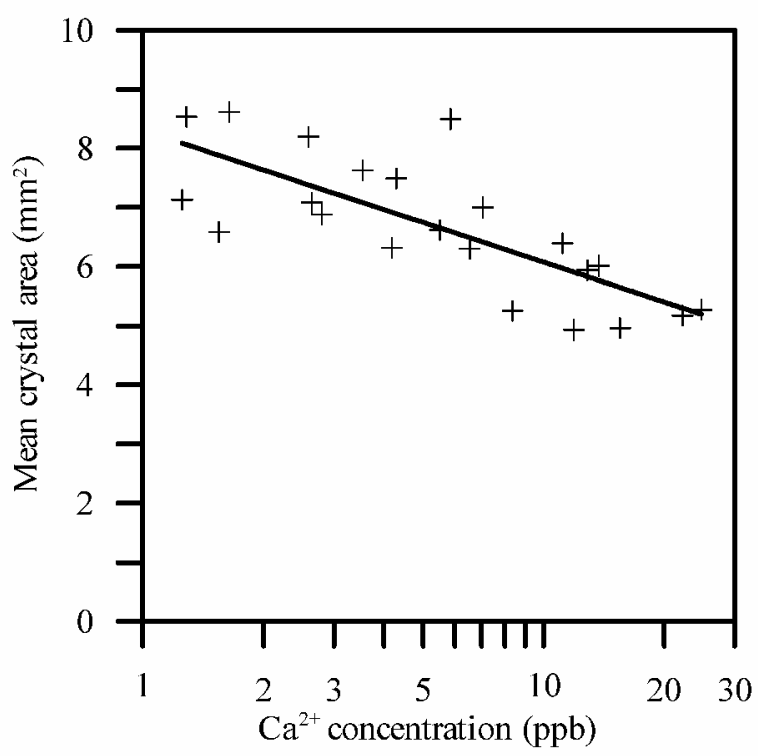

Fig. 4. Crystal area vs logarithm of $\mathrm{Ca}^{2+}$ concentration in the ice at a $5 \mathrm{~cm}$ resolution (points) and a logarithmic fit (curve). Area $=-0.97 \log \left(\mathrm{Ca}^{2+}\right)+8.31\left(R^{2}=0.58\right)$.

respectively). Although the total distribution in Figure $3 \mathrm{~b}$ is indeed close to a lognormal distribution, a slight asymmetry is noticed with a "shoulder" of smaller crystals centred around $1 \mathrm{~mm}^{2}$ (see Svensson and others, 2003, for discussion). The mean of the lognormal fit to the total distribution is $3.40 \mathrm{~mm}^{2}$, and the lognormal standard deviation is 3.05 .

\section{DISGUSSION}

The mean crystal areas are compared to the concentration of chemical impurities of $\mathrm{Ca}^{2+}, \mathrm{Na}^{+}, \mathrm{K}^{+}, \mathrm{Mg}^{2+}, \mathrm{Cl}^{-}, \mathrm{NO}_{3}$ and $\mathrm{SO}_{4}{ }^{2-}$ at a $5 \mathrm{~cm}$ resolution, which is the resolution of the chemistry measurements (Table 1). Although this resolution is limited in resolving the fast transitions in crystal sizes, which occur on a cm scale (Fig. 1), the crystal areas show quite strong anticorrelation to several of the ionic species. We find that generally the best correlation with crystal areas is obtained when applying the logarithm to the concentration of impurities. The strongest anticorrelation appears for $\mathrm{Ca}^{2+}$, but $\mathrm{Mg}^{2+}, \mathrm{Cl}^{-}, \mathrm{K}^{+}$and $\mathrm{Na}^{+}$also correlate quite strongly with crystal areas, whereas $\mathrm{NO}_{3}{ }^{-}$and $\mathrm{SO}_{4}{ }^{2-}$ show poor correlation. The crystal areas are plotted against log $\left(\mathrm{Ca}^{2+}\right)$ in Figure 4. They are also compared to the ECM signal and to the $\delta^{18} \mathrm{O}$ of the ice at a $2.5 \mathrm{~cm}$ resolution, but here no correlation is observed (Table 1 ).

The concentration of insoluble impurities (dust) in the ice has not been measured, but both $\mathrm{Ca}^{2+}$ and $\mathrm{Mg}^{2+}$ are major constituents in dust, and $\mathrm{Ca}^{2+}$ is often used as a proxy for the dust concentration of the ice (Steffensen, 1997). Because of the high anticorrelation between crystal areas and both $\mathrm{Ca}^{2+}$ and $\mathrm{Mg}^{2+}$, it is likely that the dust concentration of the ice plays a major role in controlling the crystal size variability on a seasonal time-scale.

\section{GONGLUSIONS}

A continuous $1.1 \mathrm{~m}$ long section from around $301 \mathrm{~m}$ depth of the NorthGRIP ice core has been investigated for crystal properties and for impurity concentrations. A strong seasonal variation in crystal areas is observed, with the smallest crystals appearing in spring, when the concentration of $\mathrm{Ca}^{2+}$ also has its maximum. This result suggests that it may be possible to establish an empirical relationship between crystal areas and dust concentration of Greenland Holocene ice. The crystal area distribution is very close to a lognormal distribution. The fabric of the ice does not display a detectable variation with seasons, nor does it vary as a function of crystal sizes. We thus conclude that the fabric of the ice develops independently of the texture and of the chemical impurities in the investigated ice.

\section{ACKNOWLEDGEMENTS}

This work is a contribution to the NorthGRIP ice-core project, which is directed and organized by the Department of Geophysics at the Niels Bohr Institute for Astronomy, Physics and Geophysics, University of Copenhagen. It is supported by funding agencies in Denmark, Belgium, France, Germany, Iceland, Japan, Sweden, Switzerland and the U.S.A.

\section{REFERENGES}

Alley, R. B. and G. A. Woods. 1996. Impurity influence on normal grain growth in the GISP2 ice core, Greenland. F. Glaciol., 42(141), 255-260.

Alley, R. B., J. H. Perepezko and C. R. Bentley. 1986. Grain growth in polar ice: II. Application. f. Glaciol., 32(112), 425-433.

Dahl-Jensen, D. and 8 others. 2002. The NorthGRIP deep drilling programme. Ann. Glaciol., 35, 1-4.

Gow, A. J. and 6 others. 1997. Physical and structural properties of the Greenland Ice Sheet Project 2 ice cores: a review. F. Geophys. Res., 102(C12), 26,559-26,575.

Hansen, K. M., A. Svensson, Y. Wang and J. P. Steffensen. 2002. Properties of GRIP ice crystals from around Greenland interstadial 3. Ann. Glaciol., 35, 531-537.

Johnsen, S. J. 1977. Stable isotope homogenization of polar firn and ice. International Association of Hydrological Sciences Publication 118 (Symposium at Grenoble 1975 - Isotopes and Impurities in Snow and Ice), 210-219.

Steffensen, J.P. 1988. Analysis of the seasonal variation in dust, $\mathrm{Cl}^{-}, \mathrm{NO}_{3}{ }^{-}$, and $\mathrm{SO}_{4}{ }^{2-}$ in two central Greenland firn cores. Ann. Glaciol., 10, 171-177.

Steffensen, J. P. 1997. The size distribution of microparticles from selected segments of the GRIP ice core representing different climatic periods. 7. Geophys. Res., 102(C12), 26,755-26,763.

Steffensen, J. P., H. B. Clausen, C. U. Hammer, M. Legrand and M. de Angelis. 1997. The chemical composition of cold events within the Eemian section of the Greenland Ice Core Project ice core from Summit, Greenland. 7. Geophys. Res., 102(C12), 26,747-26,754.

Svensson, A. and 6 others. 2003. Properties of ice crystals in NorthGRIP lateto middle-Holocene ice. Ann. Glaciol., 37 (see paper in this volume).

Thorsteinsson, Th., J. Kipfstuhl and H. Miller. 1997. Textures and fabrics in the GRIP ice core. F. Geophys. Res., 102(C12), 26,583-26,599.

Wang, Y., T. Thorsteinsson, J. Kipfstuhl, H. Miller, D. Dahl-Jensen and H. Shoji. 2002. A vertical girdle fabric in the NorthGRIP deep ice core. Ann. Glaciol., 35, 515-520. 